\title{
PERANAN DAN PELAKSANAAN CUSTOMER SERVICE PADA PT. BANK PEMBANGUNAN DAERAH SUMATERA BARAT CABANG PEMBANTU RSUP DR. M. DJAMIL PADANG
}

\author{
Nikita Mardhatilla, Yosep Eka Putra, SE,MSi \\ Akademi Keuangan dan Perbankan "Pembangunan" Padang
}

\begin{abstract}
The purpose of this research is to broaden the knowledge about banking, especially the role and implementation of customer service at Pt. BPD West Sumatra sub branch of RSUP Dr. M djamil padang. In analyzing the data, the writer uses descriptive method with inductive mindset which explains the results of research on the role and implementation of customer service at PT. BPD sub branch of RSUP Dr. M. djamil Padang. Customer service is a person who directly deals with customers, customer service has a role to be responsible for the service and smooth operation of the bank, especially with regard to customer service, the role of customer service in serving customers, namely in providing information on bank products and customer service attitudes in providing information, customer service ability in serving customers so that customers feel satisfied with the services provided by customer service. Customer service to customers is needed even though there are still customers who are not satisfied with customer service.
\end{abstract}

Keywords : Role, and implementation of customer service

\section{PENDAHULUAN}

Perkembangan dan kemajuan dalam dunia kerja yang sangat pesat maka diperlakukan sumber daya manusia yang memiliki keterampilan sesuai dengan kebutuhan pasar dan kompeten. Dengan kualitas sumber daya manusia yang semakin berkembang maka akan terjadi persaingan yang ketat, dimana kualitas yang baik memiliki keterampilan khusus dan pengetahuan yang luas akan lebih unggul untuk menghadapi persaingan tersebut.

Bank merupakan badan usaha yang tugasnya menghimpun dana dari masyarakat dalam bentuk simpanan dan menyalurkan kembali kepada masyarakat dalam bentuk kredit untuk meningkatkan taraf hidup ekonomi masyarakat. Oleh karena itu peranan perbankan sangatlah penting dalam perekonomian untuk memudahkan dan melancarkan berbagai sektor ekonomi di Indonesia (Kasmir, 2010).

Peran dan pelaksanaan Customer Service pada PT. Pembangunan Daerah Sumatera Barat Cabang Pembantu RSUP Dr. M. Djamil Padang yang paling utama adalah memberikan informasi dan pelayanan terbaik kepada nasabah atau pelanggan produk dan jasa. Serta menjaga hubungan baik dengan nasabah atau pelanggan produk dan jasa apabila Customer Service sedang melayani nasabah maka harus bertanggung jawab atas kepuasan nasabah. Disamping itu Customer Service juga mempunyai kendala yang dihadapinya saat melayani nasabah, antara lain ketika Customer Service dalam melayani nasabah, seharusnya berkonsentrasi pada satu nasabah yang sedang dihadapinya, namun terkadang ada seorang nasabah yang tiba-tiba datang dan meminta petugas Customer Service untuk segera melayani keperluannya, yang dipengaruhi oleh faktor yaitu tingkat pendidikan dan usia nasabah yang bervariatif terkadang menjadi hambatan Customer Service dalam memberikan 
pelayanan pada nasabah dan mengalami kelambatan sistem yang digunakan sehingga memperlambat kinerja Customer Service dalam melayani nasabah (Saogo \& Tanjung, n.d, 2019).

Berdasarkan latar belakang permasalahan di atas, maka penulis tertarik melakukan penelitian dalam bentuk tugas akhir dengan judul "Peranan dan Pelaksanaan Customer Service pada PT. Bank Pembangunan Daerah Sumatera Barat Cabang Pembantu RSUP Dr. M. Djamil Padang.

\section{Metode Penelitian}

\section{Metode Pengumpulan Data}

a. Studi Lapangan

Pada penelitian ini dilakukan dengan cara melakukan wawancara dengan pihakpihak PT. Bank Pembangunan Daerah Sumatera Barat Cabang Pembantu RSUP Dr. M. Djamil Padang.

b. Studi Kepustakaan

Penelitian ini dilakukan dengan mengumpulkan data dan menggunakan teori-teori yang berkaitan dengan masalah-masalah yang akan dibahas, berupa buku-buku yang berkaitan dengan masalah.

c. Kuesioner

Kuesioner adalah suatu bentuk teknik pengumpulan data yang dilakukan pada metode penelitian dengan tidak perlu atau/wajib memerlukan kedatangan langsung dari sumber data (Hutabalian \& Kalangi, 2015).

\section{Metode Analisa Data}

Dalam menganalisa data penulis menggunakan metode kuliatatif. Metode kualitatif adalah menggambarkan, memahami dan menjelaskan data yang diteliti selama penelitian berlangsung.

\section{ANALISA DAN PEMBAHASAN}

Menurut (Nurjayanti \& Widayati, n.d, 2019) Bank adalah Perusahaan Jasa, dengan kata lain bahwa bank adalah perusahaan yang menjual jasa kepada masyarakat. Untuk itu, bank akan memberikan pelayanan yang terbaik untuk nasabah, karena bagi bank nasabah itu adalah raja. Banyak bank yang ada di Indonesia khususnya di kota Padang menimbulkan persaingan yang sangat ketat dan berlomba untuk memperoleh tingkat yang paling baik di mata masyarakat, oleh sebab itu diperlukan strategi yang baik dan tepat oleh masing-masing lembaga guna meningkatkan laba perusahaan dan memiliki kualitas yang bermutu. Salah satu cara yang tepat adalah adanya peranan customer service dalam meningkatkan pelayanan terhadap nasabah, karena pelayanan yang bermutu merupakan kunci sukses dan dasar untuk membangun keberhasilan di perusahaan perbankan. Dalam hal ini, tidak semua karyawan bank itu berhubungan langsung dengan nasabah, karena sesuai dengan tugas dan fungsinya masing-masing. Karyawan bank paling sering dan memang tugasnya selalu berhubungan langsung dengan nasabah salah satunya adalah customer service.

Customer Service adalah sebagai ujung tombak perusahaan dalam melayani pelanggan atau nasabah dan menjual produk atau jasa yang ditawarkan, merupakan divisi terdepan dalam memberikan pelayanan kepada nasabah. Peran Customer Service sangat 
penting dalam perusahaan. Seorang Customer Service berhubungan langsung dengan pelanggan atau nasabah harus selalu bersikap ramah, sopan, bersedia mendengarkan apa yang dikatakan dan ditanyakan pelanggan atau nasabah, sabar dalam melayani, dan tidak menangguhkan suatu pelayanan yang segera dapat dilakukan. Selain itu Customer Service juga harus mampu melayani setiap pertanyaan nasabah (D. N. P. Yanti, 2013).

Peranan Customer Service memegang peranan sangat penting dalam dunia perbankan. Tugas utama seorang customer service adalah memberikan pelayanan dan membina hubungan dengan masyarakat. Customer service bank dalam melayani para nasabah selalu berusaha menarik dengan cara meyakinkan dengan para calon nasabah agar menjadi nasabah bank yang bersangkutan. Selain itu customer service juga harus dapat menjaga nasabah lama agar tetap menjadi nasabah bank (Bilqis Salsabilla, 2020). Oleh karena itu, tugas customer service menjadi tulang punggung.

\section{Persyaratan untuk Customer Service}

Untuk menjadi seorang Customer Service ia harus pintar dalam memberikan solusi untuk memecahkan suatu masalah yang dihadapi oleh nasabah.

1. Persyaratan Fisik

Seorang Customer Service harus memiliki ciri-ciri fisik yang menarik seperti tinggi dan berat badan yang ideal

2. Syarat Mental

Seorang Customer Service harus mempunyai mental yang kuat dalam hal melayani pelanggan atau nasabahnya, karena akan memberikan kepercayaan diri yang lebih baik, dan memberikan keyakinan, kejujuran dan tanggung jawab yang besar terhadap apa yang dilakukannya (Lestari, 2019).

3. Syarat Kepribadian

Seorang Customer Service harus memiliki kepribadian yang baik seperti murah senyum, sopan, lemah lembut, simpatik, lincah, energik, menyenangkan, berjiwa bisnis, memiliki rasa humor, dan ingin maju.

4. Syarat Sosial

Customer Service harus mempunyai jiwa sosial yang tinggi dan bijaksana, memiliki budi pekerti luhur, pandai bergaul dan bersosialisasi dengan siapapun dan bisa bekerjasama serta berkomitmen dengan berbagai pihak.

5. Syarat Pendidikan

Setiap instansi memiliki standar pendidikan dalam menentukan kriteria calon seorang Customer Service, tetapi lazimnya adalah berpendidikan sekurangkurangnya D3(Diploma 3) atauS1(Sarjana).

6. Syarat Tambahan

Mampu memahami materi dengan baik yang nantinya akan berkaitan dengan produk instansi tersebut.

7. Syarat Nilai

Tidak hanya nilai akademis yang dinilai dalam Customer Service tetapi juga menilai etika customer service setiap melayani nasabah dengan segenap kelebihan yang dimiliki. 


\section{Fungsi dan tugas Customer Service}

Fungsi dan tugas customer service harus dilaksanakan sebaik mungkin dalam arti dapat dilaksanakan dengan sebaik-baiknya dan harus bertanggung jawab dari awal sampai selesainya suatu pelayanan nasabah.

a. Fungsi customer service

1. Sebagai resepsionis, artinya seorang CS berfungsi sebagai penerima tamu yang datang ke bank.

2. Sebagai deskman, artinya seorang CS berfungsi sebagai orang yang melayani berbagai macam aplikasi yang diajukan nasabah atau calon nasabah.

3. Sebagai sales, artinya CS berfungsi sebagai orang yang menjual produk perbankan sekaligus sebagai pelaksana cross selling.

4. Sebagai Customer relation officer, yaitu berfungsi sebagai orang yang dapat membina hubungan baik dengan seluruh nasabah, termasuk merayu atau membujuk agar nasabah tetap bertahan tidak lari dari bank yang bersangkutan apabila menghadapi masalah.

5. Sebagai komunikator, artinya Customer service yang berfungsi sebagai orang yang menghubungi nasabah dan memberikan informasi tentang segala sesuatu yang ada hubungannya antara bank dan nasabah.

b. Tugas Customer Service

1. Melayani pembukaan rekening baru (deposito, tabungan, giro)

2. Melayani permintaan buku cek, buku bilyet giro dan buku setoran.

3. Membuat debet nota kepada nasabah giro atas pemakaian buku cek/bilyet giro.

4. Melayani informasi saldo nasabah.

5. Memberikan informasi tentang produk-produk bank.

6. Melayani komplain nasabah.

7. Menginventarisasi daftar hitam nasabah.

8. Mengadministrasikan/membuat stok buku cek dan bilyet giro.

9. Membuat laporan pembukaan rekening (tabungan dan giro)harian, bulanan, dan tahunan.

10. Membuat laporan penutupan rekening (tabungan dan giro)harian, bulanan, dan tahunan.

11. Membuat slip serah terima internal.

12. Membuat slip kolektif penerimaan setoran tunai (khusus pembelian buku cek/bilyet giro.

\section{Dasar-dasar Pelayanan Nasabah}

Seorang customer service dituntut untuk memberikan pelayanan yang prima kepada nasabahnya. Agar pelayan yang diberikan bisa memuaskan nasabah, maka seorang customer service harus memiliki dasar-dasar pelayanan yang kokoh. Pelayanan yang diberikan akan berkualitas jika setiap customer service telah dibekali dasar-dasar pelayanan. Kepuasan nasabah adalah harapan atau perasaan seseorang atas pembelian suatu barang atau jasa (Marlius \& Putriani, 2019).

1. Berpakaian dan berpenampilan rapi dan bersih

2. Percaya diri, bersikap akrab, dan penuh dengan senyum

3. Tenang, sopan, hormat serta tekun mendengarkan setiap pembicaraan . 
4. Jangan marah dan jangan mudah tersinggung.

5. Jangan mendebat nasabah

6. Jaga sikap sopan, ramah dan selalu berlaku tenang.

7. Menyapa dengan lembut dan berusaha menyebutkan nama jika kenal, pada saat datang petugas customer service harus segera menyapa dengan menyebutkan nama.

8. Tunjukan sikap perhatian dan sikap ingin membantu.

\section{Pelayanan Yang Baik Terhadap Nasabah}

1. Tersedia sarana dan prasarana yang baik Untuk melayani nasabah salah satu hal yang paling penting diperhatikan yaitu sarana dan prasarana yang dimiliki oleh bank.

2. Tersedia karyawan yang baik Kenyamanan nasabah juga tergantung pada petugas customer service yang melayaninya. Petugas customer service harus ramah, sopan, dan menarik.

3. Bertanggung jawab kepada setiap nasabah sejak awal hingga selesai Dalam menjalankan kegiatan pelayanan petugas customer service harus mampu melayani dari awal sampai tuntas atau selesai.

4. Mampu melayani secara cepat dan tepat

Dalam melayani nasabah diharapkan petugas customer service harus melakukannya sesuai prosedur.

5. Mampu berkomunikasi

Petugas customer service mampu dengan cepat memahami keinginan nasabah.

6. Memberikan jaminan kerahasiaan setiap transaksi

Petugas customer service harus mampu menjaga rahasia nasabah terhadap siapapun.

7. Memiliki pengetahuan dan kemampuan yang baik

Menurut (Situmeang \& Hidaya, n.d, 2013) Customer service harus memiliki pengetahuan dan kemampuan tertentu.

8. Mampu memberikan kepercayaan kepada nasabah

Kepercayaan calon nasabah kepada bank mutlak diperlukan sehingga calon nasabah mau menjadi nasabah yang bank yang bersangkutan.

9. Berusaha memahami kebutuhan nasabah

Customer service harus cepat tanggap apa yang di inginkan nasabah. Customer service yang lamban membuat nasabah lari usahakan mengerti dan memahami kebutuhan nasabah.

\section{Kendala dan hambatan yang dihadapi oleh Customer Service dalam melayani nasabah dan solusi mengatasi hambatannya.}

Customer Service dituntut untuk memberikan pelayanan yang baik dan sesuai standart pelayanan Customer Service yang berlaku di pada PT Bank Pembangunan Daerah Sumatera Barat Capem RSUP Dr. M. Djamil Padang. Namun, dalam melayani nasabah petugas Customer Service menghadapi kendala adapun kendala yang dihadapi oleh Customer Service, antara lain : 
a. Ketika petugas Customer Service sedang melayani nasabah seharusnya berkonsentrasi pada satu nasabah yang sedang di layani dihadapannya, namun terkadang ada seorang nasabah yang tiba-tiba datang dan meminta petugas untuk segera melayani keperluan nasabah tersebut. Atau juga ada telepon yang berdering membuat Customer Service berhenti sejenak melayani nasabah untuk mengangkat telepon tersebut.

b. Tingkat pendidikan dan usia nasabah yang bervariatif juga terkadang menjadi hambatan Customer Service dalam memberikan pelayanan pada nasabah. Misalnya, pendidikan nasabah yang rendah menyebabkan Customer Service harus memberi penjelasan yang berulang-ulang sampai nasabah tersebut paham dan dengan apa yang dimaksud Customer Service dan nasabah mampu menerima penjelasan dari Customer Service dengan jelas.

c. Hambatan lain yang dihadapi nasabah oleh Customer Service adalah pada saat melayani nasabah, tiba-tiba atasan memanggil Customer Service karena ada suatu keperluan.

\section{Penilaian Customer Service pada PT. Bank Pembangunan Daerah Sumatera Barat Cabang Pembantu RSUP Dr. M. Djamil Padang.}

Peranan Customer Service dalam memberikan pelayanan kepada nasabah, penulis melakukan pengamatan sebagai tolak ukur kualitas Customer Service pada PT. Bank Pembangunan Daerah Sumatera Barat Cabang Pembantu RSUP Dr. M. Djamil Padang. Melalui penyebaran kuesioner, penulis dapat menyimpulkan beberapa pendapat responden mengenai penilaian terhadap Customer Service dalam melayani nasabah. Dibawah ini adalah tabel hasil kuesioner pendapat responden terhadap penilaian Customer Service pada PT. Bank Pembangunan Daerah Sumatera Barat Cabang Pemabantu RSUP Dr. M. Djamil Padang. Kualitas pelayanan customer service yakni memberikan informasi yang cepat, tepat dan akurat dengan kualitas pelayanan customer service.

Dalam pengukuran kualitas pelayanan customer service terdiri dari :

1. Tangible adalah bukti konkret kemampuan suatu perusahaan untuk menampilkan yang terbaik bagi nasabah. Baik dari sisi fisik tampilan bangunan, fasilitas, perlengkapan teknologi pendukung, sampai penampilan customer service

2. Reliability adalah kemampuan perusahaan untuk memberikan pelayanan yang sesuai dengan harapan konsumen terkait kecepatan, ketepatan waktu, tidak ada kesalahan, sikap simpatik dan lain sebagainya.

3. Responsiveness adalah tanggap memberikan pelayanan yang cepat atau responsive serta diiringi dengan cara penyampaian yang jelas dan mudah dimengerti.

4. Assurance adalah jaminan dan kepastian yang diperoleh dari sikap sopan santun customer service, komunikasi yang baik, dan pengetahuan yang dimiliki, sehingga mampu menumbuhkan rasa percaya pelanggan 
5. Empathy adalah memberikan perhatian yang yang bersifat pribadi kepada nasabah, hal ini dilakukan untuk mengetahui keinginan nasabah secara akuran dan spesifik.

\section{SIMPULAN}

1. Peranan dan pelaksanaan customer service pada PT. Bank Pembangunan Daerah Sumatera Barat Cabang Pembantu RSUP Dr. M. Djamil sangat penting dalam melayani nasabah untuk melakukan interaksi dan memberikan pelayanan terhadap nasabah dan calon nasabah yang terkait dengan jasa yang akan digunakan. Customer Service secara umum ialah kegiatan yang diperuntukkan atau ditujukan untuk memberikan kepuasan dan pelayanan kepada nasabah melalui pelayanan yang dapat memenuhi keinginan yang sesuai dengan harapan dan kepuasan pelanggan.

2. Penilaian nasabah terhadap Customer Service, dapat disimpulkan beberapa pendapat responden dari hasil kuesioner bahwa dalam memberikan pelayanan terhadap nasabah Customer Service mendapat penilaian sangat baik $86 \%$, sedangkan penilaian baik sebesar $13 \%$, dan penilaian cukup baik sebesar $1 \%$.

\section{UCAPAN TERIMA KASIH}

Penulis ucapkan puji dan sykur dan sykur atas kehadirat-Nya, yang telah melimpahkan rahmat dan hidayah kepada penulis. Penulis ingin mengucapkan terima kasih yang tak terhingga atas bimbingan bapak Yosep Eka Putra, SE, Msi yang telah memberikan motivasi , masukan-masukan yang bermanfaat bagi penulis dan terima kasih untuk taman-teman atas semangat dan dukungannya dalam pembuatan artikel ini. Akhir kata penulis ucapkan terima kasih, semoga apa yang penulis tuangkan dalam karya kecil ini memberikan manfaat terutama bagi saya sendiri selaku penulis. Aamiin ya Rabbal 'alamin.

\section{DAFTAR PUSTAKA}

Barid, I. F. n.d.(2017) Peranan Customer Dalam Meningkatkan Pelayanan Terhadap Nasabah Di BTN. SEKOLAH TINGGI ILMU EKONOMI PERBANAS SURABAYA $1,1-15$.

Bilqis Salsabilla. (2020). Pelaksanaan Service Excellent Oleh Customer Service. SEKOLAH TINGGI ILMU EKONOMI PERBANAS SURABAYA.

Fernandes, Y. D., \& Marlius, D. (2018). Peranan Customer Service Dalam Meningkatkan Pelayanan Kepada Nasabah Pada PT. Bank Pembangunan Daerah Sumatera Barat Cabang Utama Padang. https://doi.org/10.31227/osf.io/wrh3p

Gammahendra, F., Hamid, D., \& Riza, M. F. (2014). Pengaruh Struktur Organisasi terhadap Efektivitas Organisasi. Fakultas Ilmu Administrasi Universitas Brawijaya Malang, 7(2), 1-10.

Hardi, F. (2017). Peranan Dan Pelayanan Customer service. SEKOLAH TINGGI ILMU EKONOMI PERBANAS SURABAYA.

Hutabalian, Y. H., \& Kalangi, J. S. (2015). Peran Customer Service Dalam Meningkatkan mutu Pelayanan Di PT. BPR. 1-10.

Karimoy, M. Y. (2019). Peranan Customer Service Dalam Meningkatkan Pelayanan Terhadap Nasabah. SEKOLAH TINGGI ILMU EKONOMI PERBANAS 
SURABAYA.

Kasmir. (2010). Kasmir. In PENGANTAR MANAJEMEN KEUANGAN (pp. 117-118).

Lestari, C. A. D. (2019). Peran Costomer Service Dalam Meningkatkan Pelayanan Terhadap Nasabah Di Bank Mandiri Cabang Pembantu Kupang Indah. Oleh: CHRISMI ANGGUN DWI LESTARI NIM : 2016110390 SEKOLAH TINGGI ILMU EKONOMI PERBANAS SURABAYA SURABAYA.

Marlius, D., \& Putriani, I. (2019). Kepuasan Nasabah PT . Bank Rakyat Indonesia Unit Tapan Cabang Painan Dilihat Dari Kualitas Layanan Customer Service. Akademi Keuangan Dan Perbankan Padang 2 Sekolah Tinggi Ilmu Ekonomi KBP, 3(2), 111-122. https://doi.org/10.31575/jp.v3v2.151

Nurjayanti, F., \& Widayati, R. n.d.(2019) Peranan Customer Service Dalam Operasional Bank Nagari Cabang Pekan Baru. Akademi Keuangan Dan Perbankan Padang, 118.

Purnomo, A. P. (2017). Pelasanaan Pelayana Customer service Di Bank bjb cabang Surabaya. SEKOLAH TINGGI ILMU EKONOMI PERBANAS SURABAYA.

Putra, Y. A. (2014). Strategi Komunikasi Efektif Customer PT. Federal Internasional Finance Dalam Memberikan Informasi Dan pelayanan Pembiayaan Motor Bekas Pada Konsumen D Bontang. Ilmu Komunikasi, 2(1), 419-433.

Saogo, B., \& Tanjung, M. S. . n.d. (2019) Aktivitas Customer Service dalam Meningkatkan Mutu Pelayanan Nasabah Pada PT. BPD Sumatera Barat. Akademi Keuangan Dan Perbankan Padang, 1-10.

Sarah Arnila, J. F. (2018). Sistim Pengendalian Kredit Untuk Mempertahankan Likuiditas Pada PT. Bank Nagari Cabang Painan. Akademi Keuangan Perbankan “Pembangunan”PadangJhonfernos@akbpstie.ac.id,1-13.

Sasqia, D. M., \& Putri. (2019). Upaya Customer Service Dalam Meningkatkan Mutu Pelayanan Terhadap Nasabah. SEKOLAH TINGGI ILMU EKONOMI PERBANAS SURABAYA.

Situmeang, I. V. O., \& Hidaya, R. n.d. (2013) Peran customer service dalam penyelenggaraan event di centro lifestyle departement store. Fakultas Ilmu Komunikasi UPI-YAI, Jakarta.

Suhari, Y. (2009). SISTEM PENDUKUNG KEPUTUSAN PEMBERIAN KREDIT PADA PT. BPR ARTAMANUNGGAL ABADI MRANGGEN. Jurnal Dinamika Informatika, 1(1).

Yanti, D. N. P. (2013). Kualitas Komunikasi Pelayanan Customer Service Di PT. Indosat, TBK Balikpapan. Ilmu Ekonomi, 1(2), 39-54.

Yanti, R. N. (2017). Kualitas Pelayanan customer service Pada Nasabah PT. BRI. SEKOLAH TINGGI ILMU PERBANAS SURABAYA 2017.

Zulfa, I. (2017). Pelaksanaan Pelayanan Prima Oleh Customer Service. SEKOLAH TINGGI ILMU EKONOMI PERBANAS SURABAYA. 